\title{
Pathogens and Global Health
}

\section{The prevalence of adaptive immunity to COVID-19 and reinfection after recovery - a comprehensive systematic review and meta-analysis}

Tawanda Chivese, Joshua T. Matizanadzo, Omran A. H. Musa, George Hindy, Luis Furuya-Kanamori, Nazmul Islam, Rafal Al-Shebly, Rana Shalaby, Mohammad Habibullah, Talal A. Al-Marwani, Rizeq F. Hourani, Ahmed D. Nawaz, Mohammad Z. Haider, Mohamed M. Emara, Farhan Cyprian \& Suhail A. R. Doi

To cite this article: Tawanda Chivese, Joshua T. Matizanadzo, Omran A. H. Musa, George Hindy, Luis Furuya-Kanamori, Nazmul Islam, Rafal Al-Shebly, Rana Shalaby, Mohammad Habibullah, Talal A. Al-Marwani, Rizeq F. Hourani, Ahmed D. Nawaz, Mohammad Z. Haider, Mohamed M. Emara, Farhan Cyprian \& Suhail A. R. Doi (2022): The prevalence of adaptive immunity to COVID-19 and reinfection after recovery - a comprehensive systematic review and meta-analysis, Pathogens and Global Health, DOI: 10.1080/20477724.2022.2029301

To link to this article: https://doi.org/10.1080/20477724.2022.2029301

曲 Published online: 31 Jan 2022.

Submit your article to this journal $\llbracket$

Q View related articles $\longleftarrow$

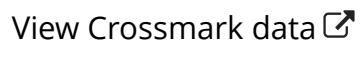




\title{
The prevalence of adaptive immunity to COVID-19 and reinfection after recovery - a comprehensive systematic review and meta-analysis
}

\author{
Tawanda Chivese (iD ${ }^{a}$, Joshua T. Matizanadzob, Omran A. H. Musa ${ }^{a}$, George Hindy ${ }^{\mathrm{a}}$, Luis Furuya-Kanamoric,

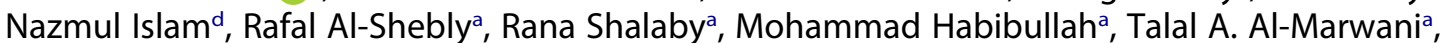 \\ Rizeq F. Hourani ${ }^{a}$, Ahmed D. Nawaz ${ }^{a}$, Mohammad Z. Haidera, Mohamed M. Emarae,f, Farhan Cyprian ${ }^{\mathrm{e}}$ \\ and Suhail A. R. Doi ${ }^{\mathrm{a}}$
}

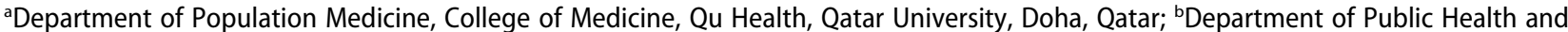
Primary Care, Brighton and Sussex Medical School, UK; CUQ Centre for Clinical Research, The University of Queensland, Herston, Australia;

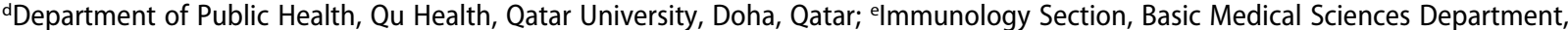
College of Medicine, Qu Health, Qatar University, Doha, Qatar; ${ }^{f}$ Microbiology Section, Biomedical and Pharmaceutical Research Unit, Qu Health, Qatar University, Doha, Qatar

\section{ABSTRACT}

This study aims to estimate the prevalence and longevity of detectable SARS-CoV-2 antibodies and T and $B$ memory cells after recovery. In addition, the prevalence of COVID-19 reinfection and the preventive efficacy of previous infection with SARS-CoV-2 were investigated. A synthesis of existing research was conducted. The Cochrane Library, the China Academic Journals Full Text Database, PubMed, and Scopus, and preprint servers were searched for studies conducted between 1 January 2020 to 1 April 2021. Included studies were assessed for methodological quality and pooled estimates of relevant outcomes were obtained in a meta-analysis using a bias adjusted synthesis method. Proportions were synthesized with the Freeman-Tukey double arcsine transformation and binary outcomes using the odds ratio (OR). Heterogeneity was assessed using the $\mathrm{I}^{2}$ and Cochran's $\mathrm{Q}$ statistics and publication bias was assessed using Doi plots. Fifty-four studies from 18 countries, with around 12,000,000 individuals, followed up to 8 months after recovery, were included. At 6-8 months after recovery, the prevalence of SARS-CoV-2 specific immunological memory remained high; lgG $-90.4 \%$ (95\%Cl 72.2-99.9, $\left.I^{2}=89.0 \%\right), C D 4+-91.7 \%$ $(95 \% \mathrm{Cl} 78.2-97.1 \mathrm{y})$, and memory B cells $80.6 \%(95 \% \mathrm{Cl} 65.0-90.2)$ and the pooled prevalence of reinfection was $0.2 \%\left(95 \% \mathrm{Cl} 0.0-0.7, \mathrm{I}^{2}=98.8\right)$. Individuals previously infected with SARS-CoV-2 had an $81 \%$ reduction in odds of a reinfection (OR $\left.0.19,95 \% \mathrm{Cl} 0.1-0.3, I^{2}=90.5 \%\right)$. Around $90 \%$ of recovered individuals had evidence of immunological memory to SARS-CoV-2, at 6-8 months after recovery and had a low risk of reinfection.

Registration

PROSPERO: CRD42020201234
KEYWORDS

COVID-19; SARS-CoV-2;

adaptive immunity; antibodies; reinfection; preventive efficacy

\section{Introduction}

Despite the availability of several efficacious and safe vaccines against COVID-19 [1,2], access to the vaccines is limited, especially for low and middle-income countries (LMICs) [3]. With the pandemic showing no signs of abating, a key question that remains unanswered is whether infection with COVID-19 confers immunity and how long that immunity lasts. If individuals with past COVID-19 infection have durable immunity, they may form a group that could be less prioritized for COVID-19 vaccination in resource-limited settings or subject to single-dose vaccination regimens in resource limited settings [4-6]. However, the nature of, the protectiveness and duration of acquired immunity to COVID-19 is still not completely understood.

CONTACT Tawanda Chivese tchivese@qu.edu.qa; sdoi@qu.edu.qa Department of Population Medicine, College of Medicine, Qu Health, Qatar University, Doha, Qatar

What is already known on this topicIndividuals who recover from COVID-19 may have immunity against future infection but the proportion who develop immunity is uncertain. Further, there is uncertainty about the proportion of individuals who get reinfected with COVID-19.What this study addsUsing data from 54 studies with follow up time up to 8 months after recovery, during the period February 2020-February 2021, we found that, post-COVID-19, up to $90 \%$ of individuals had antibodies and memory T and B cells against SARS-CoV-2. We also found a pooled prevalence of reinfection of $0.2 \%$, and that infection conferred an $81 \%$ decrease in odds of reinfection with SARS-CoV-2, compared to unimmunized individuals without previous COVID-19.This review of 12 million individuals presents evidence that most individuals who recover from COVID-19 develop immunological memory to SARS-CoV-2, which was still detectable for up to 8 months. Further, reinfection after recovery from COVID-19 was rare during the first 8 months after recovery, with a prevalence below $1 \%$, while prior infection confers protection with an odds ratio of 0.19 and a preventive efficacy of $80 \%$ at a baseline prevalence of $5 \%$ for COVID-19 in a community.Implications of all the available evidencelndividuals with a history of COVID-19 infection have immunity against the disease for up to 8 months, although this period could be longer. These individuals could be prioritized last for COVID-19 vaccinations or considered for single dose vaccinations.StrengthsThis comprehensive review addresses key questions on prevalent immunological memory and risk of reinfection in individuals with prior confirmed COVID-19 using robust systematic review methods.LimitationsSome of the included studies which examined prevalent immunological memory were small studies which were affected by loss to follow up. The review did not examine evidence for immunity against the new divergent variants, which may be more likely to have immune evasion behavior and may present a higher risk of reinfection. Lastly, the review did not examine the effect of the severity of COVID-19 on both immunological memory and the risk of reinfection.

(c) 2022 Informa UK Limited, trading as Taylor \& Francis Group 
Several studies have shown that individuals infected with SARS-CoV-2 develop neutralizing antibodies [7,8], and that, up to 8 months later, most individuals who recover from COVID-19 have evidence of humoral immunological memory [9-13]. However, many of these studies involve small numbers of participants and suffer from loss to follow up. Therefore, it is still not clear what percentage of people with COVID-19 do have detectable antibodies against SARS-CoV-2 after recovery.

There is an increasing understanding of the role played by both cellular and humoral components of the adaptive immune response against SARS-CoV-2 infection [9,14-17]. Evidence suggests that even when there are no circulating antibodies, circulating memory $T$ cells provide protection against clinical disease and death from infection by hepatitis B virus [18]. This is likely to be true for SARS-CoV-2 which can progress relatively slowly to severe disease status, in a median of about 19 days [19], as this gives the cellular immune response the time it requires to muster. Findings from the few available studies suggest that it is likely that most individuals develop immunological memory to SARS-CoV-2 in the form of CD4+ and CD8 + T cells $[9,17]$. However, it is not yet clear what proportion of people who recover from COVID-19 have detectable cellular immunological memory to SARSCoV-2 and for how long.

Measuring the proportions of individuals with evidence of immunological memory of SARS-CoV-2 gives a relatively good idea of immunity against the virus after recovery. An alternative way is through the measurement of the risk of reinfection after recovery from COVID-19. Initial findings from earlier studies suggested that reinfection with SARS-CoV-2 was not rare [20-23], and this was worsened by sensational news reporting However, a growing understanding of COVID-19 has allayed these initial fears as most of early cases were more likely to be due to either prolonged viral shedding or reactivation of an incompletely cleared virus, that may have been harbored in the nasal cavity, termed repositivity [24-26]. While repositive cases may not be as worrying as true reinfections, it is still important to understand how prevalent these cases are, and whether they are infective or not. Evidence from several case studies suggest that reinfection is still possible, with several confirmed reinfections having been reported so far $[22,23]$. Establishing reinfection prevalence is a difficult process in epidemiological studies as this requires viral sequencing from both the primary and secondary infection during large longitudinal cohorts [27], and not many studies can afford to do this on a large scale. Emerging data from a few large cohort studies [28-30] has shown that the prevalence of reinfection by SARS-CoV-2 lies anywhere between $<1 \%$ and $5 \%$. It is still not clear what proportion of individuals with COVID-19 get re-infected by the virus and if the protective immunity from previous infection by SARSCoV-2 wanes over time. Longitudinal studies of the main seasonal coronaviruses; HCoV-NL63, HCoV-229E, HCoV-OC43 and HCoV-HKU1, have shown that acquired immunity is short-lived and reinfection occurs more frequently after six to 12 months of recovery [31]. This could be due to strain variation, which increases the risk of reinfection, a situation that may be similar to SARSCoV-2 where divergent variants [32-34] have developed. Endemic human coronaviruses have seasonal outbreaks [35-38], but it is not yet clear whether SARCoV-2 will follow a similar pattern [39].

This research aims to estimate the prevalence of SARS-CoV-2 specific immunologic memory after recovery from COVID-19 and its efficacy in protecting against reinfection through synthesis of all existing research. Specifically, the research aims to estimate the prevalence of detectable SARS-CoV-2 specific lgG and IgA antibodies, memory CD4+, CD8+ and B cells after recovery, to estimate the prevalence of repositivity and reinfection after infection with SARS-CoV-2, and to estimate the protective efficacy of previous infection with SARS-CoV-2 against reinfection.

\section{Methods}

\section{Study design}

The design and conduct of this systematic review and meta-analysis followed the Preferred Reporting Items for Systematic reviews and Meta-Analyses (PRISMA) guidelines [40]. The protocol for this study is registered online on PROSPERO, the International prospective register of systematic reviews (CRD42020201234).

\section{Data sources and search methods for identification of studies}

We searched the Cochrane Library, Web of Science Clarivate, the China Academic Journals Full Text Database, PubMed, Scopus, and the databases of preprints (https://www.medrxiv.org/ and https://www. biorxiv.org/) for studies published during the period from 1 January2020 till the $1^{\text {st }}$ of April 2021, without language restrictionspublished during the period from, . All references of retrieved articles were manually screened for further studies. The search strategy is shown in Supplementary Doc 1.

\section{Procedure for selection of studies}

Articles retrieved from the search were exported to Endnote $X 7$ where duplicates were removed and then uploaded for the initial screening using the titles and abstracts on the Rayyan systematic review management website (https://www.rayyan.ai/). 
Due to the large number of records identified, records were subdivided into four groups and for each group, two investigators then screened titles, abstracts and if necessary full articles for inclusion. The full text of the records identified from screening using titles and abstracts were then screened for eligibility independently by the two investigators. Disagreements were resolved by an independent third author from another group.

\section{Criteria for considering studies for the review}

\section{Types of studies}

This synthesis included observational studies which reported the prevalence of SARS-CoV-2 specific lgG, $\lg A, C D 4+, C D 8+$ and memory $B$ cells after recovery from COVID-19, the prevalence of repositivity and reinfection with SARS-CoV-2. The study designs included were case series, cross-sectional studies and cohort studies. Studies were included if participants had COVID-19 confirmed using polymerase-chain reaction $(\mathrm{PCR})$ or molecular antigen tests. For humoral immunity, eligible studies should have assessed the presence of detectable SARS-CoV-2 specific IgG and IgA. For cellular immunity, studies were eligible if they used flow cytometry to measure proportions of individuals with SARS-CoV-2 specific CD4+, CD8+ and memory $B$ cells. Studies were excluded if they were experimental studies, as they may not be representative of cases with COVID-19, if participants did not have confirmed COVID-19 by molecular tests, if they measured immunity components during the infection phase, if they were seroprevalence studies in general populations, if time points were not clear and if the study used commercial samples which were not linked to participants.

\section{Outcomes}

For the humoral and cellular immune response, we assessed the prevalence of detectable SARS-CoV-2 specific IgG, IgA, CD4+, CD8+ and memory B cells after recovery from COVID-19. We also assessed the prevalence of reinfection and repositivity after recovery. The protective efficacy of prior infection with SARS-CoV-2 against reinfection was assessed by comparing the number of positive cases between individuals with prior COVID-19 and those without, within the same cohort.

\section{Key definitions}

We defined the post infection period as at least 21 days after symptom onset or confirmation of COVID-19 and confirmation of two negative COVID-19 PCR 24 hour apart [27]. A limitation of this definition is that individuals with long COVID could still be included, although it is estimated that this proportion is low at around $1.5 \%$ [41]. We defined SARS-CoV-2 immunity prevalence as the proportion of individuals seropositive for any of IgG, IgA, CD4+, CD8+ memory $B$ cells against any of; SARS-CoV-2 spike, spike receptor-binding domain (RBD) and the nucleocapsid at the time point measured. Notably, recent studies document that while SARS-CoV-2 spike-specific serum IgA levels decline quickly after infection, local concentrations at mucosal surfaces persist longer and include dimeric isoforms with potent neutralizing capacity $[42,43]$ and thus serum IgA may not be the best indicator of mucosal protection. For studies that reported estimates at different timepoints, we extracted data from the furthest time point.

COVID-19 reinfection is difficult to establish and is strictly defined as phylogenetically distinct genomic sequences in the first and second episodes [27]. It is becoming apparent that some recovered people may have a positive COVID-19 because of prolonged viral shedding. We defined repositivity as any positive PCR test within the first 3 months after a PCR negative tested recovery from COVID-19. Because very few population-based studies have been able to establish reinfection using genetic sequencing, and therefore distinguish reinfection from a chronic infection reservoir, we considered all participants who test positive on PCR for COVID-19 after being confirmed negative, or full clinical recovery with a negative COVID-19 test at least 3 months after recovery, according to the United States Centers for Disease Control criteria [27]. One drawback is that this definition could possibly result in an under-estimation of reinfection rates.

The efficacy of prior infection with SARS-CoV-2 in protection against future infection was defined similar to the vaccination effect, by calculation of the relative risk reduction. However, the relative risk reduction was recomputed from the odds ratio (OR) using the Stata module logittorisk given that the synthesis needs to be done $[44,45]$ on the OR scale.

\section{Data extraction}

From each included study, two reviewers extracted data on study characteristics such as study authors, country of study, study setting, timepoints measured, length of follow-up, gender distribution, and mean or median age of participants. Because of the high number of studies included and the difficulties in locating the data that were required for this synthesis, the studies were grouped into four groups and a third author was required to double check extracted data from each pair of reviewers. To estimate the prevalence of adaptive immune responses, repositivity and reinfection, we extracted data on numbers of individuals, out of the total with confirmed COVID-19, with circulating SARS-CoV-2 specific $\lg G, \lg A, C D 4+$, CD8+, 
memory B cells, and numbers of individuals who had a positive RT-PCR after confirmed recovery from COVID-19 at least 3 months post their initial diagnosis. If a study reported data on multiple timepoints, we extracted data from the latest timepoints. For each study we also extracted data on the type of test used to detect IgG, CD4+, CD8+ and memory B cells and which SARS-CoV-2 antigen (spike protein, spike RBD or nucleocapsid) the antibodies or cells were specific to.

\section{Assessment of the quality of and risk of bias in included studies}

Two investigators independently assessed the included articles for methodological quality using the updated MethodologicAl STandard for Epidemiological Research (MASTER) scale (analytical studies) [46] and the tool described by Hoy et al, (prevalence studies) [47]. Any differences were resolved by discussion and a third investigator was consulted if they failed to reach consensus. The tool by Hoy et al [47], has ten items which assess external validity (items 1-4) and internal validity (items 5-9) since external validity is part of methodological quality for prevalence studies. The MASTER tool was used to assess the quality of analytical studies which assessed the effect of prior infection on the risk of reinfection with SARS-CoV-2. The MASTER scale has 36 items assessing seven quality domains which are; equal recruitment (items 1-4), equal retention (items 5-9), equal ascertainment (items 10-16), equal implementation (items 17-22), equal prognosis (items 23-28), sufficient analysis (items 29-31) and temporal precedence (items 32-36).

\section{Data synthesis}

We used tables to show descriptive data of included studies. For the prevalence objectives, we recalculated prevalence estimates from each study using the number of cases with detectable SARS-CoV -2 specific lgG, IgA, CD4+, CD8+, memory B cells and cases with positive PCR (reinfection) after recovery from COVID-19 that was at or later than 3 months post recovery from COVID-19. We also carried out subgroup analysis of prevalence in the post-recovery period using three periods of 0-2 months, 3-5 months and at least 6 months. We used the quality effects model [48] to pool prevalence from studies, as it maintains a correct coverage probability and a less mean squared error when compared to the random effects model, when there is heterogeneity across studies [49].

We used the Freeman-Tukey double arcsine transformation [50] to stabilize the variances in all prevalence data. To investigate the protective effect of prior COVID-
19 on the risk of reinfection, we calculated unadjusted odds ratios from included studies. Results of metaanalyses were presented in tables and forest plots.

Between study heterogeneity was investigated using the $\mathrm{I}^{2}$ statistic and Cochran's $\mathrm{Q}$ p-values and exact $p$-values were presented. Heterogeneity was considered low $\left(\mathrm{I}^{2}\right.$ below 50\%), moderate $\left(\mathrm{I}^{2}\right.$ between $50 \%$ and $75 \%)$ and high $\left(1^{2}\right.$ above $\left.75 \%\right)$. Doi plots [39] were used to visually assess small study effects in lieu of funnel plots as they are more reliable and easier to interpret. The LFK index was used to quantify Doi plot asymmetry. We used the metan package in Stata IC version 15 software [51] for all analyses.

\section{Ethics and dissemination}

This study utilized published data and did not require ethical approval.

\section{Patient and public involvement}

It was not appropriate or possible to involve patients or the public in the design, or conduct, or reporting, or dissemination plans of our research

\section{Results}

\section{Search results and characteristics of included studies}

A total of 9706 records were identified from database searches and a final 54 studies $[8-12,16,17,24-26,30,52-$ 94] from 18 countries were included after exclusion of ineligible studies (Figure 1). The total number of individuals from included studies were around 12,000,000 individuals. Most $(n=23)$ of the studies were from China, eight were from the USA and the remaining were from several other countries (Figure 2). The followup times ranged from 2 weeks to 8 months after recovery from COVID-19, and the studies were carried out during the period February 2020-February 2021. Twenty-four of the studies were case series, twenty were cohort studies, eight were cross-sectional and the remaining two were case-control studies. Most of the studies ( $n=38$ ) were hospital-based, 14 were carried out in the community and the remaining study was in healthcare workers only. Four $[11,16,57,69]$ of the included studies were preprints at the time of publication of this review. The characteristics of the included studies are shown in Supplementary Table 1.

\section{Assessment of internal validity and applicability}

Using the Hoy risk of bias tool most of the studies ( $n=44)[8,9,12,16,17,24-26,30,52,54,55,58,60,61,63-$ $69,71-75,77-83,87,88,90-95]$ were classified as 


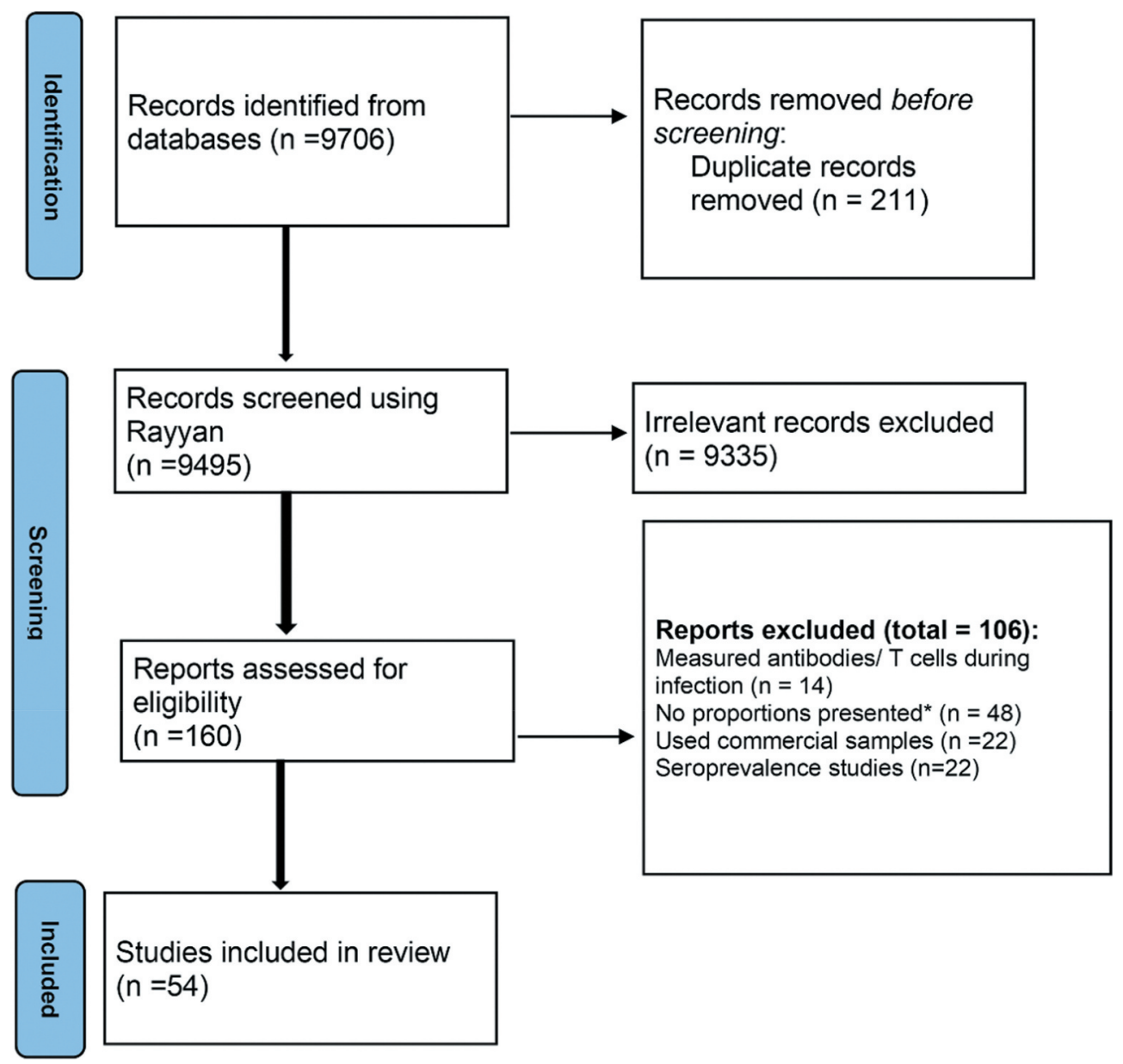

Figure 1. Flow chart showing the search and inclusion of studies.

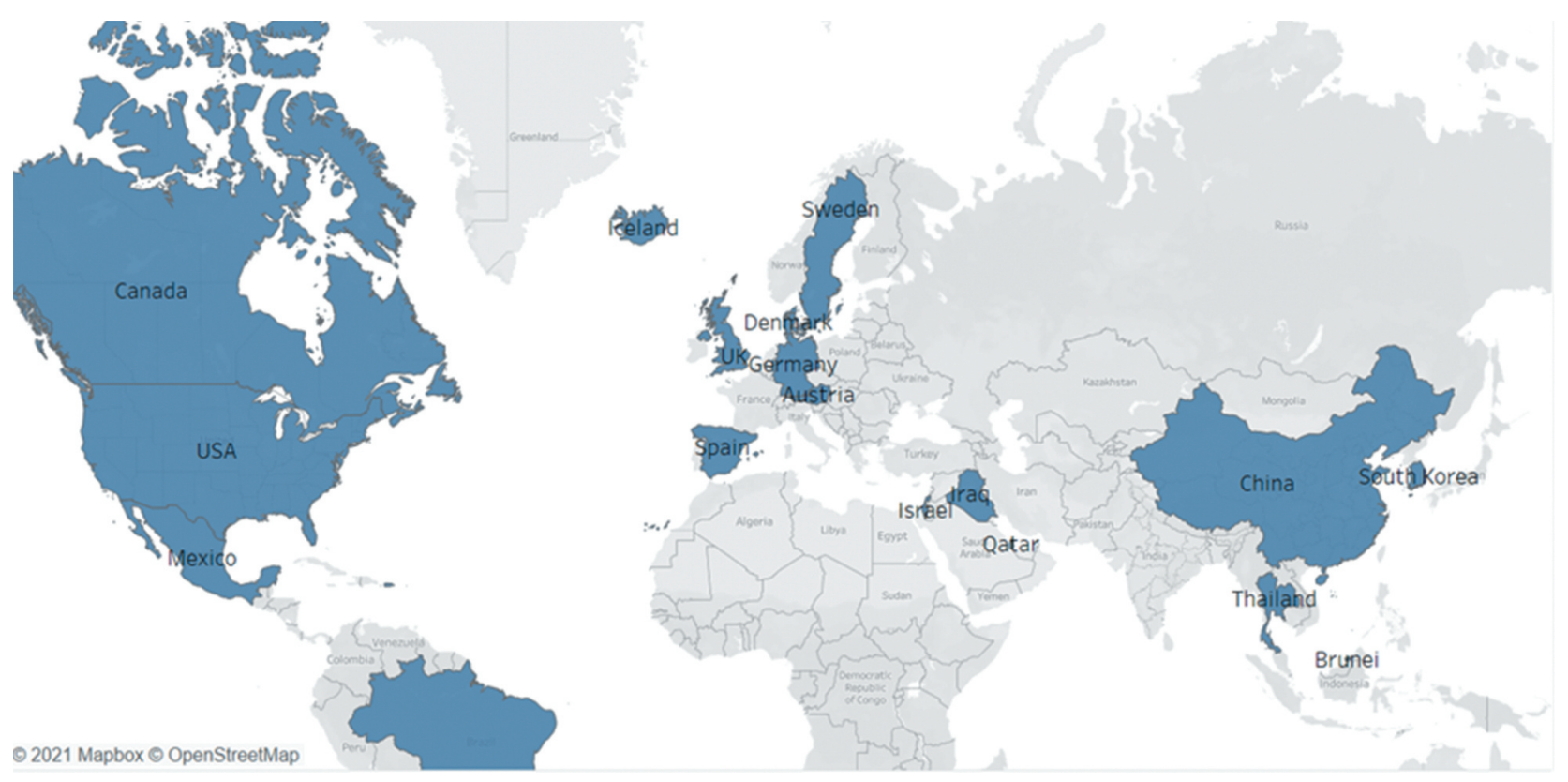

Figure 2. Map showing country of origin of included studies.

moderate risk, seven studies $[11,53,56,57,62,86,89]$ as high risk and three studies $[10,60,70]$ as low risk (Supplementary Table 2). The included studies had deficiencies in items related to external validity (Supplementary Table 2). The exceptions were a few studies where some forms of total sampling were employed. These included one Chinese study where the whole City of Wuhan was screened for COVID-19 after the first Chinese lockdown [10], an Austrian study where almost everyone in the country [70] was tested 
and a study of nearly four million people in Denmark [60]. There were five studies $[30,54,59,70,74]$ which compared new COVID-19 cases between individuals with prior infection and those without on reinfection/ new infection which we assessed using the MASTER tool. The MASTER safeguard counts ranged from 14 to 21 out of a possible 36 , with deficiencies in most of the studies, due to their observational nature, in the domains of equal recruitment, equal retention, equal ascertainment and equal prognosis (Supplementary Table 3).

\section{Prevalence of SARS-CoV-2 specific IgG and IgA antibodies after recovery from COVID-19}

Data from 26 studies $[8,9,11,12,16,17,56-$ $59,61,62,65,68,71,73,75,77,80,83,84,86,88,90]$, with 3092 participants were available for evaluation of the prevalence of detectable IgG after recovery. The pooled prevalence of detectable IgG after recovery was $89.0 \%\left(95 \% \mathrm{Cl} 72.8-99.0, \mathrm{l}^{2}=89.7 \%, \mathrm{p}<0.01,8\right.$ studies) within 1 month, $92.6 \%(95 \% \mathrm{Cl} 86.9-96.9$, $\mathrm{I}^{2}=57.7 \%, \mathrm{p}<0.01,4$ studies $)$ at $>1-<3$ months, $91.4 \%\left(95 \% \mathrm{Cl} 84.5-96.3, \mathrm{I}^{2}=84.3 \%, \mathrm{p}<0.01,9\right.$ studies) at $3-<6$ months and $90.4 \%(95 \% \mathrm{Cl} 72.2-99.9$, $\mathrm{I}^{2}=89.0 \%, \mathrm{p}<0.01,5$ studies) beyond 6 months (Figure 3 and Supplementary Figure 1-4). There was no downward trend seen across these periods.

Only one study [69] reported data on the prevalence of SARS-CoV-2 specific IgA antibodies after recovery, with an estimate of $63.4 \%(95 \% \mathrm{Cl} 58.3-68.3)$ at 3 months after recovery.
Prevalence of SARS-CoV-2 specific CD4+ and CD8 + after recovery from COVID-19

Data from four studies $[9,16,17,73]$, three from the USA and one from the UK, with a total of 118 participants resulted in a synthesized prevalence of detectable CD4 + T cells after recovery of $100 \%$ $(95 \% \mathrm{Cl} 83.9$ - 100.0) within 1 month [17], 93.3\% (95\% Cl 70.2-98.8) between 1 and 2 months USA [54], 78.8\% $(95 \% \mathrm{Cl} 65.1-88.0)$ at 4.5 months [16] and $91.7 \%(95 \% \mathrm{Cl} 78.2-97.1)$ at $6-8$ months [7] (Figure 3 and Supplementary Figure. 5). Conversely, SARS-CoV-2 specific CD8 + T cells showed a steady decline after recovery from $70.0 \%$ (95\% Cl 48.1-85.5) within 1 month [17] to 50\% (95\% $\mathrm{Cl}$ 34.5-65.5) at 6-8 months after recovery [7] (Figure 3 and Supplementary Figure 6).

\section{Prevalence of SARS-CoV-2 specific memory B cells after recovery from COVID-19}

Two studies [9,67], both from the USA, reported data on the prevalence of SARS-CoV-2 specific memory B cells. In one study [67], most participants (prevalence 92.9\%, 95\% Cl 68.5-98.7) had anti spikeRBD class switched memory B cells, between 2 to 3 months after recovery from COVID-19. The same pattern was observed in the other study [9], with $80.6 \%(95 \% \mathrm{Cl} 65.0-90.2)$ of the participants having RBD-specific memory B cells at 4-5 months.

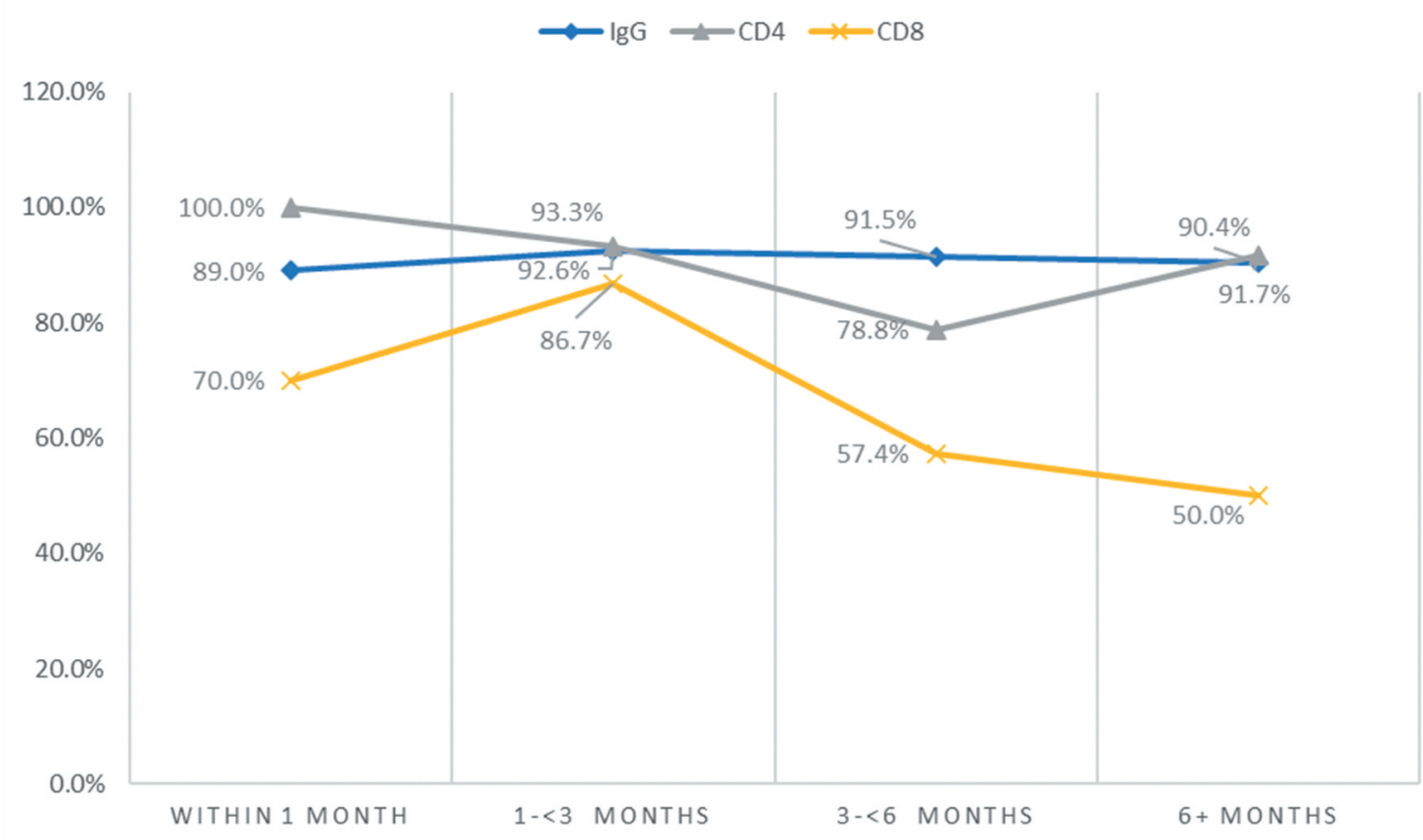

Figure 3. Prevalence of SARS-CoV-2 specific IgG, memory CD4+ and CD8+ cells after recovery from COVID-19. 


\section{Reinfection after recovery from COVID-19}

Nine studies, two from the UK $[30,54]$, and the remaining studies each from the USA [74], Austria [70], Denmark [60], Spain [96], Iraq [88], Qatar [87] and disputed territories [69], with a total of 257,448 participants, reported data on the prevalence of reinfection $\geq 3$ after recovery from COVID-19. The reported prevalence ranged from $0.0 \%$ in Spain [52] to $5.7 \%$ in the USA [70] (Figure 4). The pooled prevalence of reinfection was $0.2 \%(95 \% \mathrm{Cl} 0.0-0.7)$ with high heterogeneity $\left(I^{2}=98.8 \%, p<0.01\right)$ (Figure 4). There was gross study asymmetry with smaller studies favoring more reinfection (Supplementary Figure 7).

In contrast to reinfection, the pooled prevalence of repositivity within 1 month was $0.9 \%(95 \% \mathrm{Cl} 0.0-8.0$, $\mathrm{I}^{2}=99.8 \%, \mathrm{p}<0.01,17$ studies, Supplementary Figure 8$)$. The pooled prevalence of COVID-19 repositivity at 2-3 months after recovery was $0.1 \%(95 \% \mathrm{Cl}$ $0.0-0.7,7$ studies), with substantial heterogeneity $\left(I^{2}=99.7 \%, p<0.01\right)$ and also gross study asymmetry with smaller studies favoring more repositivity (Supplementary Figure 9).

\section{Comparison of risk of SARS-CoV-2 infection between individuals with and those without prior infection}

Five studies with a total of 11,459,882 individuals compared infection with SARS-CoV-2 between individuals with a previous confirmed COVID-19 diagnosis and those who had no prior infection. Two of the studies were from the UK $[30,54]$, and one study each from Austria [70], Denmark [60] and the USA [74], and all the studies followed up participants for at least 7 months.
The odds ratio of infection by SARS-CoV-2 in individuals with prior COVID-19 compared to those without prior infection ranged from 0.06 in a study [76] from the UK to 0.41 in a study [80] from the USA (Table 1).

In pooled analysis, the odds ratio for infection in individuals with compared to without prior COVID-19 was $0.19(95 \% \mathrm{Cl} 0.11-0.32)$, with significant heterogeneity $\left(I^{2}=94.5, p<0.01\right)$ (Figure 5$)$. The studies were asymmetrical with smaller studies favoring less reinfection (Supplementary Figure 10). Assuming a baseline risk of primary infection of $5 \%$, this odds ratio translates (using logit to risk) to a relative risk reduction of $80.2 \%$ (95\%Cl 66.9-88.5\%).

\section{Discussion}

In this synthesis of 54 studies with follow-up times up to 8 months and carried out during the period February 2020-February 2021, we found a high prevalence of detectable SARS-CoV-2 specific immunological memory in the form of IgG antibodies, CD4+, and memory $B$ cells in individuals who recovered from COVID-19. We found that the prevalence of reinfection after recovery from COVID-19 was very low and that prior infection with SARS-CoV-2 conferred an $80 \%$ protective efficacy against reinfection (assuming baseline prevalence of 5\%). The existing reviews [23,97-106] have not examined the question of prevalent immunity sufficiently (Supplementary Table 4).

The results of this study suggest that there is a sustained high prevalence of SARS-CoV-2 specific IgG antibodies, near $90 \%$, up to 6-8 months after recovery from COVID-19, and data from one study showed a prevalence of $\lg A$ of $63 \%$ after recovery. Although we assessed the prevalence of detectable IgG, and not the actual antibody titers, research in primates has shown that even low circulating

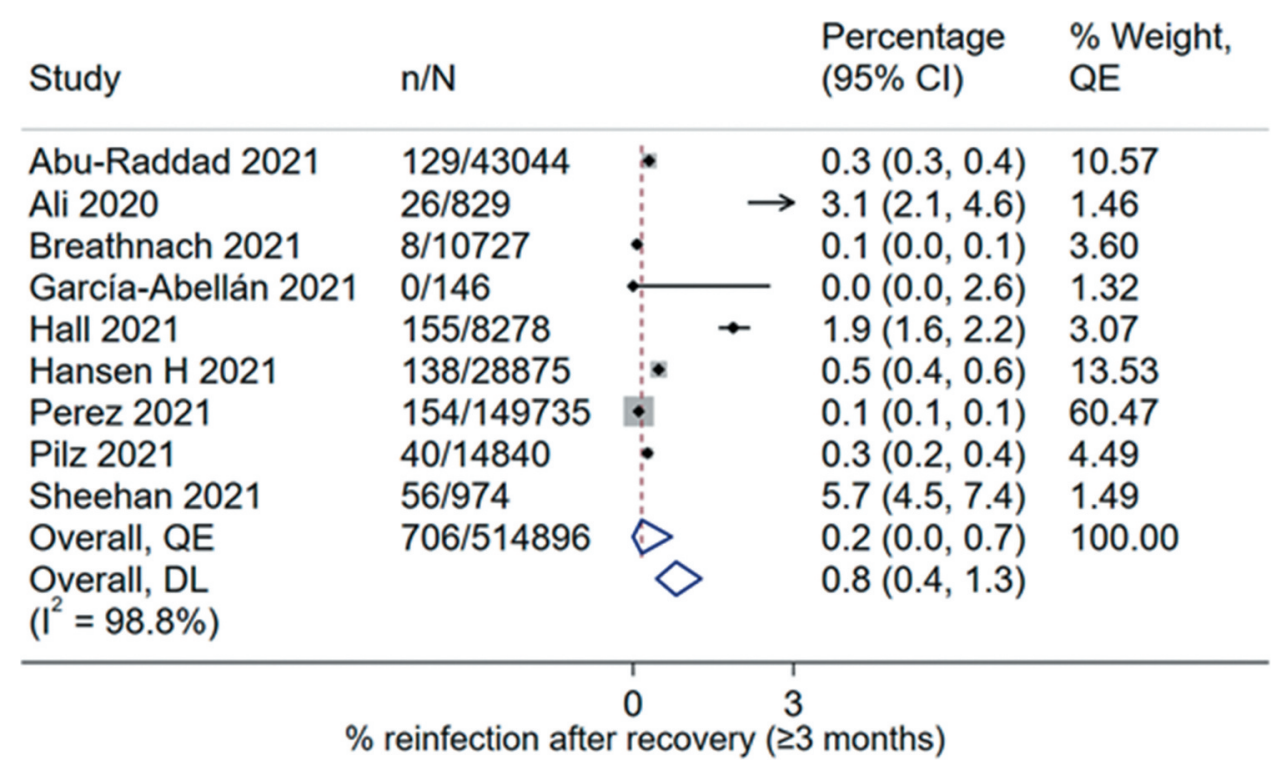

Figure 4. Prevalence of SARS-CoV-2 reinfection $\geq 3$ months after recovery from COVID-19. 
Table 1. Studies comparing risk of infection by SARS-CoV-2 between previously infected and uninfected individuals.

\begin{tabular}{|c|c|c|c|c|c|c|c|}
\hline Study & Sample size & Country & $\begin{array}{l}\text { Follow up } \\
\text { length }\end{array}$ & Period & $\begin{array}{l}\text { Reported effect } \\
\text { measure and size }\end{array}$ & Confounders adjusted for & $\begin{array}{c}\text { Recomputed } \\
\text { odds ratio }\end{array}$ \\
\hline $\begin{array}{l}\text { Pilz } 2021 \\
\quad[70]\end{array}$ & $\begin{array}{c}14,840 \text { exposed, } \\
8,885,640 \\
\text { unexposed }\end{array}$ & Austria & $>7$ months & $\begin{array}{l}\text { February } 2020- \\
\text { November } 2020\end{array}$ & $\begin{array}{l}\text { Odds ratio } 0.09 \\
(95 \% \mathrm{Cl} 0.07- \\
0.13)\end{array}$ & None & $\begin{array}{r}0.09(95 \% \mathrm{Cl} \\
0.07-0.13)\end{array}$ \\
\hline $\begin{array}{l}\text { Breathnach } \\
2021 \text { [54] }\end{array}$ & $\begin{array}{c}10,727 \text { exposed, } \\
55,274 \\
\text { unexposed }\end{array}$ & UK & 8 months & $\begin{array}{l}\text { February } 2020 \text { - } \\
\text { December } 2020\end{array}$ & $\begin{array}{c}\text { Relative risk } 0.06 \\
(95 \% \mathrm{Cl}: 0.03- \\
0.12)\end{array}$ & None & $\begin{array}{c}0.06 \\
(95 \% \mathrm{Cl}: \\
0.03-0.11)\end{array}$ \\
\hline $\begin{array}{l}\text { Sheehan } \\
2021 \text { [74] }\end{array}$ & $\begin{array}{l}974 \text { exposed, } \\
32,208 \\
\text { unexposed }\end{array}$ & USA & $\geq 8$ months & $\begin{array}{l}\text { March } 2020- \\
\text { February } 2021\end{array}$ & $\begin{array}{c}\text { Risk ratio } 0.22 \\
(95 \% \mathrm{Cl} 0.18- \\
0.28)\end{array}$ & None & $\begin{array}{c}0.41 \\
(95 \% \mathrm{Cl} \\
0.31-0.54)\end{array}$ \\
\hline $\begin{array}{l}\text { Hansen } \\
2021 \text { [60] }\end{array}$ & $\begin{array}{c}28,875 \text { exposed, } \\
2,405,683 \\
\text { unexposed }\end{array}$ & Denmark & $>7$ months & $\begin{array}{l}\text { March } 2020 \text { - } \\
\text { December } 2020\end{array}$ & $\begin{array}{c}0.20(95 \% \mathrm{Cl} 0.16- \\
0.25)\end{array}$ & Age, gender, and frequency of tests & $\begin{array}{c}0.21 \\
(95 \% \mathrm{Cl}: \\
0.18-0.25)\end{array}$ \\
\hline $\begin{array}{l}\text { Hall } 2021 \\
\quad[30]\end{array}$ & $\begin{array}{c}8278 \text { exposed, } \\
17,383 \\
\text { unexposed }\end{array}$ & UK & 7 months & $\begin{array}{l}\text { June } 2020- \\
\text { January } 2021\end{array}$ & $\begin{array}{l}\text { Incidence rate } \\
\text { ratio } 0.16(95 \% \\
\mathrm{Cl} 0.13-0.19)\end{array}$ & $\begin{array}{l}\text { Age, gender, ethnicity, region, staff } \\
\text { group, hospital site, index of } \\
\text { multiple deprivation }\end{array}$ & $\begin{array}{c}0.18 \\
(95 \% \mathrm{Cl}: \\
0.15-0.21)\end{array}$ \\
\hline
\end{tabular}

*Exposed were previously infected and unexposed were previously uninfected individuals

neutralizing antibody tires had a protective effect against COVID-19 [107,108]. This protective effect could be at the level of reducing severe COVID-19 and death from COVID-19, rather than stopping the infection in the upper respiratory tract. Sterilizing immunity that stops individuals from acquiring infec- study, more than 100 times those of naïve individuals [5]. The findings from this current synthesis add to this body of knowledge and support single-dose vaccination for individuals with prior infection.

This synthesis suggests, for a period of at least 68 months after recovery, around $90 \%$ of individuals

\begin{tabular}{|c|c|c|c|c|}
\hline Study & No. pts & & $\begin{array}{l}\text { Odds Ratio } \\
(95 \% \mathrm{Cl})\end{array}$ & $\begin{array}{l}\% \text { Weight, } \\
\text { QE }\end{array}$ \\
\hline Breathnach 2021 & 66001 & $\rightarrow$ & $0.06(0.03,0.11)$ & 3.89 \\
\hline Hall 2021 & 25661 & + & $0.18(0.15,0.21)$ & 32.88 \\
\hline Hansen H 2021 & 2434558 & + & $0.21(0.18,0.25)$ & 40.24 \\
\hline Pilz 2021 & 8900480 & $\rightarrow$ & $0.09(0.07,0.13)$ & 9.58 \\
\hline Sheehan 2021 & 33182 & $\rightarrow$ & $0.41(0.31,0.54)$ & 13.41 \\
\hline Overall, QE & 11459882 & $>$ & $0.19(0.11,0.32)$ & 100.00 \\
\hline $\begin{array}{l}\text { Overall, DL } \\
\left(I^{2}=93.9 \%\right)\end{array}$ & & & $0.16(0.10,0.25)$ & \\
\hline
\end{tabular}

Figure 5. Pooled odds ratio of infection with SARS-CoV-2 in individuals with prior COVID-19 compared with those without prior infection.

tion requires high antibody titers [9], however the level of antibody titers that provides sterilizing immunity is still not known. Therefore, it is still theoretically possible that individuals with detectable IgG may be infected by and are able to spread SARS-CoV-2. Longitudinal studies are needed to investigate the relationship between antibody titers and the risk of reinfection. Notably, it appears that the SARS-CoV-2 antibody titers are stable after recovery with a halflife of almost 5 months for spike IgG [9]. Further, several studies $[5,6,109,110]$ have shown that, regardless of either antibody titer or the presence of detectable $\lg G$ in individuals with prior infection, the levels of $\lg G$ and neutralizing antibodies after a first dose vaccination, reached titers similar to those of SARS-CoV-2 naïve individuals after a second dose, and, in one have evidence of SARS-CoV-2 specific memory B and memory CD4+ cells while about half have evidence of CD8+ cells. While the role of T cells in sterilizing immunity is thought to be limited, they are highly associated with ensuring less severe COVID-19 [73,111]. A diminished prevalence of cytotoxic CD8+ cells may imply that viral clearance is delayed in some individuals, in the event of reinfection. However, there is evidence of sustained high prevalence of $T$ follicular helper cells (TFH) [9], a subset of CD4 + T cells that are the most important in helping memory $B$ cells and in the production of neutralizing antibodies and longterm humoral immunity [99]. A high prevalence of memory $B$ cells at $\geq 6$ months also suggests that immunological memory may be long lasting, at least to the time points measured in the included studies. 
This synthesis suggests that although repeat testpositives are likely to occur in about $2 \%$ of individuals within 1 month of recovery, the prevalence of reinfection with SARS-CoV- 2 is low, with only $0.2 \%$ reinfected during a period of up to 8 months after recovery. Further, prior infection with SARS-CoV-2 provides protection against reinfection with an efficacy of $80 \%$, during the same period. While the presence of antibodies and memory $T$ and $B$ cells are evidence of immunological memory, prevalent reinfection is a stronger measure of clinical protection of prior infection [70]. In a letter to the editor published at the time of finalization of this review, the prevalence of reinfection in a period of up to 12 months was $0.3 \%$ in Italy [112]. Findings from this Italian study [101] also suggested a strong protective efficacy of prior infection with a hazard ratio of $0.06(95 \% \mathrm{Cl} 0.005-0.08)$. In the USA, another study of 9119 individuals [113] with serial tests at least 90 days apart, during December 2019 to November 2020, published at the time of finalization of this review, also showed a low prevalence of reinfection of $0.7 \%(95 \% \mathrm{Cl} 0.5-0.9)$ [89]. More research is also needed to measure protective efficacy in the long term.

A key consideration is that most of the studies in this synthesis included individuals infected with the original variant of SARS-CoV-2 and had follow-up periods during the year 2020, which may not have covered exposure to new variants. The substantial changes to the SARS-CoV-2 spike protein and the RBD domain in the new variants [32-34], with the delta variant currently being dominant globally [114], may adversely affect immunological memory and increase the risk of reinfection. For example, high case counts and hospitalizations were observed in Manaus, Brazil, 7 months after seroprevalence data suggested that three-quarters of the population were previously infected with SARS-CoV -2 [115], suggesting that a large proportion of the population was still susceptible to infection by SARSCoV-2 [116]. While it is likely that the seroprevalence study overestimated the proportion infected with SARS-CoV-2, it is also equally likely that the resurgence in Manaus could have been driven by the emergence of the highly divergent and transmissible gamma (P1) variant which was first reported from Manaus $[32,116]$. Divergent lineages of SARS-CoV-2 are more likely to be associated with antigenic escape [116] and therefore result in higher chances of reinfection. Estimates of reinfection with divergent variants such as delta and Omicron are therefore unknown, and more research is required.

Our research has several limitations, one of which is that these findings cannot be extended beyond the time of follow-up of the included studies. Another limitation is the heterogeneity in the studies that we included which was not reduced by subgroup analyses in measurements methods and follow-up times. Many of the longitudinal studies in this meta-analysis suffered from loss to follow up and this may have affected their findings. Further, although we included a comprehensive number of studies, studies on the cellular immune response are lacking and the ones we included had very small sample sizes, implying that our estimates of this aspect of the adaptive immune response may change with the accumulation of more data. Many of the included studies were small observational studies that are easily affected by confounding. Lastly, the review did not examine evidence for immunity against the new variants and did not include studies with longer follow-up.

\section{Conclusion}

This synthesis shows around $90 \%$ of individuals have evidence of SARS-CoV-2 specific immunological memory. Further, the risk of reinfection is rare and in the first 6-8 months after infection, risk of re-infection decreased by $80 \%$, though that could diminish after 8 months.

\section{Acknowledgments}

Open Access funding provided by the Qatar National Library.

\section{Disclosure statement}

No potential conflict of interest was reported by the author(s).

\section{Funding}

The author(s) reported there is no funding associated with the work featured in this article.

\section{ORCID}

Tawanda Chivese (D) http://orcid.org/0000-0001-6621-6144

\section{CRediT Authors' contributions}

TC - Conceptualisation, data curation, formal analysis, investigation, methodology, validation, resources, software, visualisation, writing - original draft, and writing - review \& editing

JTM - Data curation, investigation, formal analysis, visualization, writing - review \& editing

OAHM - Data curation, investigation, formal analysis, methodology, writing - review \& editing

LFK - Investigation, methodology, formal analysis, writing review \& editing

$\mathrm{NI}$ - Data curation, investigation, writing - review \& editing

RA - Data curation, investigation, formal analysis, writing review \& editing

RS - Data curation, investigation, formal analysis, writing review \& editing

$\mathrm{MH}$ - Data curation, investigation, formal analysis, writing - review \& editing 
TA - Data curation, investigation, formal analysis, writing review \& editing

RFH - Data curation, investigation, formal analysis, writing - review \& editing

ADN - Data curation, investigation, formal analysis, writing - review \& editing

$\mathrm{MZH}$ - Data curation, investigation, formal analysis, writing - review \& editing

MME - Conceptualisation, investigation, writing - review \& editing

FC - Conceptualisation, investigation, writing - review \& editing

SARD - Conceptualisation, formal analysis, investigation, methodology, resources, software, supervision, validation, visualisation, writing - review \& editing

All authors critically reviewed the final manuscript.

TC and SARD had full access to and verified the data

\section{References}

[1] Polack FP, Thomas SJ, Kitchin N, et al. Safety and efficacy of the BNT162b2 mRNA Covid-19 vaccine. N Engl J Med. 2020;383(27):2603-2615.

[2] Voysey M, Clemens SAC, Madhi SA, et al. Safety and efficacy of the ChAdOx1 nCoV-19 vaccine (AZD1222) against SARS-CoV-2: an interim analysis of four randomised controlled trials in Brazil, South Africa, and the UK. Lancet. 2021397 (10269) 99-111 doi:10.1016/ S0140-6736(20)32661-1 .

[3] Burki T. Equitable distribution of COVID-19 vaccines. Lancet Infect Dis. 2021;21(1):33-34.

[4] Krammer F, Srivastava K, Simon VJM. Antibody Responses in Seropositive Persons after a Single Dose of SARS-CoV-2 mRNA Vaccine N Engl J Med . 2021384 (14) 1372-1374 doi:https://doi.org/10.1101/ 2021.01.29.21250653.

[5] Manisty C, Otter AD, Treibel TA, et al. Antibody response to first $B N T 162 \mathrm{~b} 2$ dose in previously SARS-CoV-2-infected individuals. Lancet. 2021;397 (10279):1057-1058.

[6] Gobbi F, Buonfrate D, Moro L, et al. Antibody Response to the BNT162b2 mRNA COVID-19 Vaccine in Subjects with Prior SARS-CoV-2 Infection. Viruses. 2021;13 (3):422.

[7] Case JB, Rothlauf PW, Chen RE, et al. Neutralizing Antibody and Soluble ACE2 Inhibition of a Replication-Competent VSV-SARS-CoV-2 and a Clinical Isolate of SARS-CoV-2. Cell Host Microbe. 2020;28(3):475-85.e5.

[8] Ko J-H, Joo E-J, Park S-J, et al. Neutralizing Antibody Production in Asymptomatic and Mild COVID-19 Patients, in Comparison with Pneumonic COVID-19 Patients. J Clin Med. 2020;9(7):2268.

[9] Dan JM, Mateus J, Kato Y, et al. Immunological memory to SARS-CoV-2 assessed for up to 8 months after infection. Science. 2021;371(6529):eabf4063.

[10] Cao S, Gan Y, Wang C, et al. Post-lockdown SARS-CoV-2 nucleic acid screening in nearly ten million residents of Wuhan, China. Nat Commun. 2020;11(1):5917.

[11] Havervall S, Falk AJ, Klingström J, et al. SARS-CoV-2 induces a durable and antigen specific humoral immunity after asymptomatic to mild COVID-19 infection. PLoS One. $2021 \quad 17$ (1) doi:10.1371/journal. pone.0262169 Jan 03;21249162.
[12] Gudbjartsson DF, Norddahl GL, Melsted P, et al. Humoral Immune Response to SARS-CoV-2 in Iceland. N Engl J Med. 2020;383(18):1724-1734.

[13] Wajnberg A, Amanat F, Firpo A, et al. Robust neutralizing antibodies to SARS-CoV-2 infection persist for months. Science. 2020;370(6521):1227-1230.

[14] Ni L, Ye F, Cheng M-L, et al. Detection of SARS-CoV2-Specific Humoral and Cellular Immunity in COVID-19 Convalescent Individuals. Immunity. 2020;52(6):971-7. e3.

[15] None H, Zhang X, Li X, et al. Circulating cytokines and lymphocyte subsets in patients who have recovered from COVID-192020.

[16] Fendler A, Au L, Boos LA, et al. Adaptive immunity and neutralizing antibodies against SARS-CoV-2 variants of concern following vaccination in patients with cancer: the CAPTURE study. Nat Cancer 20212 . 1321-1337 doi:10.1038/s43018-021-00274-w. .

[17] Grifoni A, Weiskopf D, Ramirez SI, et al. Targets of T Cell Responses to SARS-CoV-2 Coronavirus in Humans with COVID-19 Disease and Unexposed Individuals. Cell. 2020;181(7):1489-501.e15.

[18] Van Damme P, Van Herck K. A review of the long-term protection after hepatitis $A$ and $B$ vaccination. Travel Med Infect Dis. 2007;5(2):79-84.

[19] Zhou F, Yu T, Du R, et al. Clinical course and risk factors for mortality of adult inpatients with COVID-19 in Wuhan, China: a retrospective cohort study. Lancet. 2020;395(10229):1054-1062. London, England

[20] Gousseff M, Penot P, Gallay L, et al. Clinical recurrences of COVID-19 symptoms after recovery: viral relapse, reinfection or inflammatory rebound? J Infect. 2020;81(5):816-846.

[21] Nachmias V, Fusman R, Mann S, et al. The first case of documented Covid-19 reinfection in Israel. IDCases. 2020;22:e00970.

[22] Lee KB, Kang CK, Jun Kl, et al. Immunogenicity of Influenza Vaccination in Patients with Cancer Receiving Immune Checkpoint Inhibitors. Clin Infect Dis. 2020;71(2):422-425.

[23] Iwasaki A. What reinfections mean for COVID-19. Lancet Infect Dis. 2021;21(1):3-5.

[24] Abdullah MS, Chong PL, Asli R, et al. Post discharge positive re-tests in COVID-19: common but clinically non-significant. Infect Dis (Auckl). 2020;52 (10):743-745.

[25] An J, Liao X, Xiao T, et al. Clinical characteristics of recovered COVID-19 patients with re-detectable positive RNA test. Ann Transl Med. 2020;8(17):1084.

[26] Hamed E, Sedeeq S, Alnuaimi AS, et al. Rates of recurrent positive SARS-CoV-2 swab results among patients attending primary care in Qatar. J Infect. 2021;82 (4):84-123.

[27] Centers for Disease Control. Common Investigation Protocol for Investigating Suspected SARS-CoV-2 Reinfection 202027 Oct 2020 [Available from: https://www.cdc.gov/coronavirus/2019-ncov/php/rein fection.html .

[28] Abu-Raddad LJ, Chemaitelly H, Coyle P, et al. SARS-CoV -2 reinfection in a cohort of 43,000 antibody-positive individuals followed for up to 35 weeks. EClinicalMedicine. 100861 doi:10.1016/j. eclinm.2021.100861. 202135 . 
[29] Ali AM, Ali KM, Fatah MH, et al. SARS-CoV-2 Reinfection in Patients Negative for Immunoglobulin G Following Recovery from COVID-19. New Microbes New Infect. 202043 100926 doi:10.1016/j.nmni.2021.100926 November 20.

[30] Hall VJ, Foulkes S, Charlett A, et al. SARS-CoV-2 infection rates of antibody-positive compared with antibody-negative health-care workers in England: a large, multicentre, prospective cohort study (SIREN). Lancet. 2021;397(10283):1459-1469.

[31] Edridge AW, Kaczorowska J, Hoste AC, et al. Seasonal coronavirus protective immunity is short-lasting. Nat Med. 2020;26(11):1691-1693.

[32] Faria NR, Claro IM, Candido D, et al. Genomic characterisation of an emergent SARS-CoV-2 lineage in Manaus: preliminary findings SCIENCE . 2021372 (6544) 815-821 doi:10.1126/science.abh2644 .

[33] World Health Organization. Tracking SARS-CoV-2 variants 2021 updated 2021 Aug 13. Available from: https://www.who.int/en/activities/tracking-SARS-CoV -2-variants/.

[34] Tegally H, Wilkinson E, Giovanetti M, et al. Detection of a SARS-CoV-2 variant of concern in South Africa. Nature 592 (7854) . 438-443 doi:10.1038/s41586-02103402-9.

[35] Altizer S, Dobson A, Hosseini P, et al. Seasonality and the dynamics of infectious diseases. Ecol Lett. 2006;9 (4):467-484.

[36] Fisman DN. Seasonality of infectious diseases. Annual review of public health. Annu Rev Public Health. 2007;28:127-143.

[37] Lal A, Hales S, French N, et al. Seasonality in human zoonotic enteric diseases: a systematic review. PloS One. 2012;7(4):e31883.

[38] Martinez ME, Kline KA. The calendar of epidemics: seasonal cycles of infectious diseases. PLoS Pathog. 2018;14(11):e1007327.

[39] Kronfeld-Schor N, Stevenson TJ, Nickbakhsh S, et al. Drivers of Infectious Disease Seasonality: potential Implications for COVID-19. J Biol Rhythms. 2021;36 (1):35-54.

[40] Page MJ, Moher D, Bossuyt PM, et al. PRISMA 2020 explanation and elaboration: updated guidance and exemplars for reporting systematic reviews. Bmj. 2021 $372 ; 372: n 160$ doi: 10.1136/bmj.n160.

[41] Djons A. Prevalence of ongoing symptoms following coronavirus (COVID-19) infection in the UK. Office for National Statistics - United Kingdom . 2021 Accessed 30 April 2021 https://www.semiosis.at/wp-content/ uploads/2021/06/Prevalence-of-ongoing-symptomsfollowing-coronavirus-COVID-19-infection-in-the-UK1-April-2021.pdf

[42] Sterlin D, Mathian A, Miyara M, et al. IgA dominates the early neutralizing antibody response to SARS-CoV-2. Sci Transl Med. 2021;13(577). DOI:10.1126/scitranslmed.abd2223.

[43] Wang Z, Lorenzi JCC, Muecksch F, et al. Enhanced SARS-CoV-2 neutralization by dimeric IgA. Sci Transl Med. 2021;13(577). DOI:10.1126/scitranslmed.abf1555.

[44] Doi SA, Furuya-Kanamori L, Xu C, et al. Questionable utility of the relative risk in clinical research: a call for change to practice. J Clin Epidemiol. 2020. DOI:10.1016/j.jclinepi.2020.08.019
[45] Doi SA, Furuya-Kanamori L, Xu C, et al. The OR is "portable" but not the RR: time to do away with the log link in binomial regression J Clin Epidemiol . 2021 S0895-4356 (21) 00241-9 doi:https://doi.org/10.1016/ j.jclinepi.2021.08.003.

[46] Stone JC, Glass K, Clark J, et al. The MethodologicAl STandards for Epidemiological Research (MASTER) scale demonstrated a unified framework for bias assessment. J Clin Epidemiol. 2021;134:52-64.

[47] Hoy D, Brooks P, Woolf A, et al. Assessing risk of bias in prevalence studies: modification of an existing tool and evidence of interrater agreement. J Clin Epidemiol. 2012;65(9):934-939.

[48] Doi SA, Barendregt JJ, Khan S, et al. Advances in the meta-analysis of heterogeneous clinical trials I: the inverse variance heterogeneity model. Contemp Clin Trials. 2015;45:130-138.

[49] Harris RJ, Deeks JJ, Altman DG, et al. Metan: fixed-and random-effects meta-analysis The Stata Journal . 2008;8(1):3-28 doi:https://doi.org/10.1177/ 2F1536867X0800800102.

[50] Freeman MF. Tukey JWJTAoMS. Transformations related to the angular and the square root The Annals of Mathematical Statistics . $195021 ; 607-611$ http://www.jstor.org/stable/2236611.

[51] Stata Press. Stata Statistical Software. College Station: Stata Corporation; 2016.

[52] Abu-Raddad LJ, Chemaitelly H, Malek JA, et al. Assessment of the risk of SARS-CoV-2 reinfection in an intense re-exposure setting. Clin Infect Dis. 202073 (7) 1830-1840 doi:https://doi.org/10.1093/ cid/ciaa18461102021.

[53] Dos Santos L A, PGdG F, Silva AMF, et al. Recurrent COVID-19 including evidence of reinfection and enhanced severity in thirty Brazilian healthcare workers. J Infect. 2021;82(3):399-406.

[54] Breathnach AS, Riley PA, Cotter MP, et al. Prior COVID-19 significantly reduces the risk of subsequent infection, but reinfections are seen after eight months. J Infect. 2021;82(4):e11-e2.

[55] Cao H, Ruan L, Liu J, et al. The clinical characteristic of eight patients of COVID-19 with positive RT-PCR test after discharge. J Med Virol. 2020;92 (10):2159-2164.

[56] Chirathaworn C, Sripramote $M$, Chalongviriyalert $P$, et al. SARS-CoV-2 RNA shedding in recovered COVID-19 cases and the presence of antibodies against SARS-CoV-2 in recovered COVID-19 cases and close contacts, Thailand, April-June 2020. PloS One. 2020;15(10):e0236905.

[57] De Giorgi V, West KA, Henning AN, et al. Anti-SARSCoV-2 Serology persistence over time in COVID-19 Convalescent Plasma Donors. medRxiv.2021; 21253093 doi:10.1101/2021.03.08.21253093. 2021 .

[58] Fischer B, Lindenkamp C, Lichtenberg C, et al. Evidence of long-lasting humoral and cellular immunity against SARS-CoV-2 even in elderly COVID-19 convalescents showing a mild to moderate disease progression. Life. $2021 \quad 11 \quad$ (8) 805 doi:https://doi.org/10.3390/ life11080805.

[59] Hansen CB, Jarlhelt I, Pérez-Alós L, et al. SARS-CoV-2 Antibody Responses Are Correlated to Disease Severity in COVID-19 Convalescent Individuals. J Immunol. 2021;206(1):109. 
[60] Hansen CH, Michlmayr D, Gubbels SM, et al. Assessment of protection against reinfection with SARS-CoV-2 among 4 million PCR-tested individuals in Denmark in 2020: a population-level observational study. Lancet. 2021;397(10280):1204-1212.

[61] Huynh A, Arnold DM, Smith JW, et al. Characteristics of Anti-SARS-CoV-2 Antibodies in Recovered COVID-19 Subjects. Viruses. 2021;13(4):697.

[62] Jia R, Wang X, Liu P, et al. Mild Cytokine Elevation, Moderate CD4+ $T$ Cell Response and Abundant Antibody Production in Children with COVID-19. Virol Sin. 2020;35(6):734-743.

[63] Jiang M, Li Y, Han M, et al. Recurrent PCR positivity after hospital discharge of people with coronavirus disease 2019 (COVID-19). J Infect. 2020;81(1):147-178.

[64] Li Y, Hu Y, Yu Y, et al. Positive result of Sars-Cov-2 in faeces and sputum from discharged patients with COVID-19 in Yiwu, China. J Med Virol. 2020;92 (10):1938-1947.

[65] Liu T, Wu S, Zeng G, et al. Recurrent positive SARS-CoV2: immune certificate may not be valid. J Med Virol. 2020;92(11):2384-2386.

[66] Murillo-Zamora E, Mendoza-Cano O, Delgado-Enciso I, et al. Predictors of severe symptomatic laboratory-confirmed SARS-CoV-2 reinfection. Public Health. 2021;193:113-115.

[67] Ogega CO, Skinner NE, Blair PW, et al. Durable SARS-CoV-2 B cell immunity after mild or severe disease. J Clin Invest. 2021;131(7). DOI:10.1172/ JCl145516.

[68] Peng P, Hu J, H-j D, et al. Changes in the humoral immunity response in SARS-CoV-2 convalescent patients over 8 months. Cell Mol Immunol. 2021;18 (2):490-491.

[69] Perez G, Banon T, Gazit S, et al. A 1 to 1000 SARS-CoV-2 reinfection proportion in members of a large healthcare provider in Israel: a preliminary report. medRxiv. 21253051 doi:https://doi.org/10.1101/ 2021.03.06.21253051. .

[70] Pilz S, Chakeri A, loannidis JPA, et al. SARS-CoV-2 re-infection risk in Austria. Eur J Clin Invest. 2021;51 (4):e13520.

[71] Prévost J, Gasser R, Beaudoin-Bussières G, et al. CrossSectional Evaluation of Humoral Responses against SARS-CoV-2 Spike. Cell Reports Medicine. 2020;1 (7):100126.

[72] Qiao X-M, Xu X-F, Zi H, et al. Re-positive Cases of Nucleic Acid Tests in Discharged Patients With COVID-19: a Follow-Up Study. Front Med (Lausanne). 2020;7:349.

[73] Rydyznski Moderbacher C, Ramirez SI, Dan JM, et al. Antigen-Specific Adaptive Immunity to SARS-CoV-2 in Acute COVID-19 and Associations with Age and Disease Severity. Cell. 2020;183(4):996-1012.e19.

[74] Sheehan MM, Reddy AJ, Rothberg MB. Reinfection Rates Among Patients Who Previously Tested Positive for Coronavirus Disease 2019: a Retrospective Cohort Study. Clinl Infect Dis. 2021;73(10):1882-1886.

[75] Shu H, Wang S, Ruan S, et al. Dynamic Changes of Antibodies to SARS-CoV-2 in COVID-19 Patients at Early Stage of Outbreak. Virol Sin. 2020;35 (6):744-751.

[76] Wu X, Wang Z, He Z, et al. A follow-up study shows no new infections caused by patients with repeat positive of COVID-19 in Wuhan. medRxiv 2020 . 20232892 doi: https://doi.org/10.1101/2020.11.18.20232892. r.
[77] Xiang F, Wang X, He X, et al. Antibody Detection and Dynamic Characteristics in Patients With Coronavirus Disease 2019. Clinl Infect Dis. 2020;71 (8):1930-1934.

[78] Xiao AT, Tong YX, Zhang S. False negative of RT-PCR and prolonged nucleic acid conversion in COVID-19: rather than recurrence. J Med Virol. 2020;92 (10):1755-1756.

[79] Ye G, Pan Z, Pan Y, et al. Clinical characteristics of severe acute respiratory syndrome coronavirus 2 reactivation. J Infect. 2020;80(5):e14-e7.

[80] Yuan B, Liu H-Q, Yang Z-R, et al. Recurrence of positive SARS-CoV-2 viral RNA in recovered COVID-19 patients during medical isolation observation. Sci Rep. 2020;10 (1):11887.

[81] Yuan J, Kou S, Liang Y, et al. Polymerase Chain Reaction Assays Reverted to Positive in 25 Discharged Patients With COVID-19. Clin Infect Dis. 2020;71(16):2230-2232.

[82] Zhang G, Nie S, Zhang Z, et al. Longitudinal Change of Severe Acute Respiratory Syndrome Coronavirus 2 Antibodies in Patients with Coronavirus Disease 2019. J Infect Dis. 2020;222(2):183-188.

[83] Zhao J, Yuan Q, Wang H, et al. Antibody Responses to SARS-CoV-2 in Patients With Novel Coronavirus Disease 2019. Clinl Infect Dis. 2020;71 (16):2027-2034.

[84] Y-m Z, Y-m S, W-b S, et al. Follow-up study of the pulmonary function and related physiological characteristics of COVID-19 survivors three months after recovery. EClinicalMedicine. 2020;25.

[85] Zheng Kl, Wang X-B, Jin X-H, et al. A Case Series of Recurrent Viral RNA Positivity in Recovered COVID-19 Chinese Patients. J Gen Intern Med. 2020;35 (7):2205-2206.

[86] Zhu H, Fu L, Jin $Y$, et al. Clinical features of COVID-19 convalescent patients with re-positive nucleic acid detection. J Clin Lab Anal. 2020;34(7): e23392.

[87] Abu-Raddad LJ, Chemaitelly H, Coyle P, et al. SARS-CoV -2 antibody-positivity protects against reinfection for at least seven months with $95 \%$ efficacy. EClinicalMedicine. 2021;35:100861.

[88] Ali AM, Ali KM, Fatah MH, et al. SARS-CoV-2 reinfection in patients negative for immunoglobulin $\mathrm{G}$ following recovery from COVID-19. New Microbes New Infect. 2021;43:100926.

[89] Chen J, Xu X, Hu J, et al. Clinical course and risk factors for recurrence of positive SARS-CoV-2 RNA: a retrospective cohort study from Wuhan, China. Aging. 2020;12(17):16675.

[90] García-Abellán J, Padilla S, Fernández-González M, et al. Antibody Response to SARS-CoV-2 is Associated with Long-term Clinical Outcome in Patients with COVID-19: a Longitudinal Study. J Clin Immunol. 2021;41(7):1490-1501.

[91] Huang J, Zheng L, Li Z, et al. Kinetics of SARS-CoV-2 positivity of infected and recovered patients from a single center. Sci Rep. 2020;10(1):18629.

[92] Olea B, Albert E, Torres I, et al. Adaptive immune responses to SARS-CoV-2 in recovered severe COVID-19 patients. J Clin Virol. 2021;142:104943.

[93] Wong J, Koh WC, Momin RN, et al. Probable causes and risk factors for positive SARS-CoV-2 test in recovered patients: evidence from Brunei Darussalam. J Med Virol. 2020;92(11):2847-2851. 
[94] Wu X, Wang Z, He Z, et al. A follow-up study shows that recovered patients with re-positive PCR test in Wuhan may not be infectious. BMC Med. 2021;19 (1):77.

[95] Wu J, Liu X, Liu J, et al. Coronavirus Disease 2019 Test Results After Clinical Recovery and Hospital Discharge Among Patients in China. JAMA Network Open. 2020;3 (5):e209759-e.

[96] García-Abellán J, Padilla S, Fernández-González M, et al. Long-term clinical, virological and immunological outcomes in patients hospitalized for COVID-19: antibody response predicts long COVID. medRxiv. 21253124 doi:https://doi.org/10.1101/ 2021.03.08.21253124. 2021 March 8.

[97] Iwamura APD, Tavares Da Silva MR, Hümmelgen AL, et al. Immunity and inflammatory biomarkers in COVID-19: a systematic review. Reviews in Medical Virology. 2021;31(4):e2199.

[98] Shrotri M, van Schalkwyk MCl, Post N, et al. T cell response to SARS-CoV-2 infection in humans: a systematic review. PloS One. 2021;16(1):e0245532.

[99] Yan W, Chen D, Bigambo FM, et al. Differences of blood cells, lymphocyte subsets and cytokines in COVID-19 patients with different clinical stages: a network meta-analysis. BMC Infect Dis. 2021;21(1):156.

[100] Váncsa S, Dembrovszky F, Farkas N, et al. Repeated SARS-CoV-2 Positivity: analysis of 123 Cases. Viruses. 2021;13(3):512. 10.3390/v13030512.

[101] Farrukh L, Mumtaz A, Sana MK. How strong is the evidence that it is possible to get SARS-CoV-2 twice? Reviews in medical virology 315 . 1-12 doi:https://doi. org/10.1002/rmv.2203.

[102] Arafkas M, Khosrawipour T, Kocbach P, et al. Current meta-analysis does not support the possibility of COVID-19 reinfections. Journal of Medical Virology. 2021;93(3):1599-1604.

[103] Bwire GM, Njiro BJ. A systematic review on the levels of antibodies in COVID-19 virus exposed but negative newborns: a possible vertical transmission of $\mathrm{lgG} /$ IgM. medRxiv doi:https://doi.org/10.1101/ 2020.06.09.20127118. 2020 June 09.

[104] Piri SM, Edalatfar M, Shool S, et al. A systematic review on the recurrence of SARS-CoV-2 virus: frequency, risk factors, and possible explanations. Infect Dis (Auckl). 2021;53(5):315-324.

[105] Choudhary MC, Crain CR, Qiu X, et al. Severe Acute Respiratory Syndrome Coronavirus 2 (SARS-CoV-2) Sequence Characteristics of Coronavirus Disease 2019 (COVID-19) Persistence and Reinfection. Clinl Infect Dis. 2021. DOI:10.1093/cid/ciab380
[106] Váncsa S, Dembrovszky F, Farkas N, et al. Repeated SARS-CoV-2 Positivity: analysis of 123 Cases. Viruses. 2021;13(3):512. 10.3390/v13030512.

[107] $\mathrm{Yu}$ J, Tostanoski LH, Peter L, et al. DNA vaccine protection against SARS-CoV-2 in rhesus macaques. Science. 2020;369(6505):806-811.

[108] Gao Q, Bao L, Mao H, et al. Development of an inactivated vaccine candidate for SARS-CoV-2. Science. 2020;369(6499):77-81.

[109] Abu Jabal K, Ben-Amram H, Beiruti K, et al. Impact of age, ethnicity, sex and prior infection status on immunogenicity following a single dose of the BNT162b2 mRNA COVID-19 vaccine: real-world evidence from healthcare workers, Israel, December 2020 to January 2021.Euro Surveill 26(6) December 2021 Jan 2021 10.2807/1560-7917. ES.2021.26.6.2100096

[110] Prendecki M, Clarke C, Brown J, et al. Effect of previous SARS-CoV-2 infection on humoral and T-cell responses to single-dose BNT162b2 vaccine. Lancet. 2021;397(10280):1178-1181. London, England

[111] Crotty S. T Follicular Helper Cell Biology: a Decade of Discovery and Diseases. Immunity. 2019;50 (5):1132-1148.

[112] Vitale J, Mumoli N, Clerici P, et al. Assessment of SARS-CoV-2 Reinfection 1 Year After Primary Infection in a Population in Lombardy, Italy. JAMA Internal Medicine. 2021;181(10):1407.

[113] Qureshi Al, Baskett WI, Huang W, et al. Reinfection With Severe Acute Respiratory Syndrome Coronavirus 2 (SARS-CoV-2) in Patients Undergoing Serial Laboratory Testing. Clinl Infect Dis. 2021. DOI:10.1093/cid/ciab345

[114] World Health Organization. COVID-19 Weekly Epidemiological Update 2021 Accessed 17 August 2021 [Available from: https://www.who.int/publica tions/m/item/weekly-epidemiological-update-oncovid-19-17-august-2021 .

[115] Buss LF, Prete CA, Abrahim CMM, et al. Threequarters attack rate of SARS-CoV-2 in the Brazilian Amazon during a largely unmitigated epidemic. Science (New York, N.Y.). 2021;371 (6526):288-292.

[116] Sabino EC, Buss LF, Carvalho MPS, et al. Resurgence of COVID-19 in Manaus, Brazil, despite high seroprevalence. Lancet (London, England). 2021;397(10273):452-455. 